\title{
Microalgas, produtos e aplicações
}

\author{
Microalgae, products and applications
}

\author{
Roberto Bianchini Derner ${ }^{1}$ Silvana Ohse $^{2}$ Maurício Villela $^{3}$ \\ Sabrina Matos de Carvalho ${ }^{4}$ Roseane Fett $^{5}$
}

\section{- REVISÃO BIBLIOGRÁFICA -}

\section{RESUMO}

Nos últimos anos, muito interesse tem sido focado no potencial biotecnológico das microalgas, principalmente devido à identificação de diversas substâncias sintetizadas por estes organismos. A imensa biodiversidade e conseqüente variabilidade na composição bioquímica da biomassa obtida das culturas microalgais, aliadas ao emprego de melhoramento genético e ao estabelecimento de tecnologia de cultivo em grande escala, vêm permitindo que determinadas espécies sejam comercialmente utilizadas. Nesse sentido, cultivos de microalgas têm sido realizados visando à produção de biomassa tanto para uso na elaboração de alimentos quanto para a obtenção de compostos naturais com alto valor no mercado mundial. Dentre os inúmeros compostos extraídos, ou com potencial de exploração comercial, podem ser relacionados ácidos graxos poliinsaturados, carotenóides, ficobilinas, polissacarídeos, vitaminas, esteróis e diversos compostos bioativos naturais (antioxidantes, redutores do colesterol etc.), os quais podem ser empregados especialmente no desenvolvimento de alimentos funcionais, por suas propriedades nutricionais e farmacêuticas.

Palavras-chave: biotecnologia, microalgas, compostos bioativos naturais, alimentos funcionais.

\section{ABSTRACT}

In recent years, much interest has been focused on the biotechnological potential of microalgae, mainly due the identification of several substances synthesized by these organisms. The great biodiversity and consequent variability in the biochemical composition of the biomass obtained from the microalgal cultures, allied to the genetic improvement and to the establishment of technology in massive production, have allowed various species to be commercially cultivated. In this sense, microalgae cultivations have been developed aiming at the biomass production not only for use in the food elaboration but also for the obtainment of natural compounds with high value in the world market. Among the main extracted substances, or with potential of commercial exploration, can be related polyunsaturated fatty acids, carotenoids, phycobilins, polysaccharides, vitamins, sterols and several bioactive compounds (antioxidants, cholesterol reducers etc.), the which ones can be especially used in the development of functional food, for its nutritional and pharmaceutical properties.

Key words: biotechnology, microalgae, natural bioactive compounds, nutraceutics.

\section{INTRODUÇÃO}

O crescente interesse no estudo de microrganismos como microalgas, alguns fungos (leveduras, por exemplo) e bactérias deve-se à essencial importância destes nas diversas cadeias tróficas e na

${ }^{1}$ Programa de Pós-graduação em Ciência dos Alimentos (PGCAL), Departamento de Ciência de Alimentos (CAL), Centro de Ciências Agrárias (CCA), Universidade Federal de Santa Catarina (UFSC). Autor para correspondência: Laboratório de Camarões Marinhos, Departamento de Aqüicultura (AQI), CCA, UFSC, Beco do Coroas s/n, Barra da Lagoa, CP 10.136, 88062-601, Florianópolis, Santa Catarina, Brasil. E-mail: robertoderner@1cm.ufsc.br.

${ }^{2}$ Fundação de Amparo à Pesquisa e Extensão Universitária (FAPEU). Projeto Petrobras / UFSC / FAPEU - Projeto 360/02, Florianópolis, SC, Brasil.

${ }^{3}$ Curso de Graduação em Engenharia de Aqüicultura, AQI, CCA, UFSC, Florianópolis, SC, Brasil.

${ }^{4}$ PGCAL, CAL, CCA, UFSC, Florianópolis, SC, Brasil

${ }^{5} \mathrm{CAL}, \mathrm{CCA}$, UFSC, Florianópolis, SC, Brasil. 
possibilidade da aplicação comercial em distintas áreas como na nutrição, na saúde humana e animal, no tratamento de águas residuais, na produção de energia e na obtenção de compostos de interesse das indústrias alimentar, química e farmacêutica, dentre outras (BOROWITZKA, 1993; CERTIK \& SHIMIZU, 1999; KIRK \& BEHRENS, 1999; LEMAN, 1997; BRUNO, 2001; GROBBELAAR, 2004; RICHMOND, 2004).

Atualmente, as pesquisas em biotecnologia alimentar empregando microalgas vêm ganhando especial atenção; no entanto, a coleta e o cultivo para utilização na alimentação humana são realizados há séculos (RICHMOND, 1988). Segundo o mesmo autor, povos nativos do Chade, na África, e do lago Texcoco (Astecas), no México, alimentavam-se de produtos feitos com biomassa de Spirulina spp. Bory, (Cyanophyceae) e, ainda hoje, os nativos do Chade, em determinadas épocas do ano, dependem quase que exclusivamente da coleta desta microalga para sua alimentação (JOURDAN, 1996).

Várias espécies são cultivadas comercialmente em alguns países e a biomassa produzida tem sido utilizada como fonte de produtos para aplicação na indústria de alimentos. Segundo PULZ \& GROSS (2004), o mercado de alimentos funcionais, utilizando microalgas em massas, pães, iogurtes e bebidas, apresenta rápido desenvolvimento em países como França, Estados Unidos, China e Tailândia. As principais microalgas cultivadas comercialmente são espécies dos gêneros Chlorella Beyerinck, (Chlorophyceae) e Arthrospira Stizenberger (Cyanophyceae) para a adição em alimentos naturais ("health food"), Dunaliella salina Teodoresco, (Chlorophyceae) para a obtenção de betacaroteno e Haematococcus pluvialis Flotow (Chlorophyceae) para a obtenção de astaxantina (BECKER, 2004).

Esta revisão apresenta uma atualização sobre a produção comercial das microalgas e considerações sobre o potencial de aplicação biotecnológica, sobre as principais espécies empregadas comercialmente e dos compostos de interesse industrial, especialmente dos ácidos graxos poliinsaturados e dos carotenóides.

\section{Algumas das carcterísticas das microalgas}

O termo microalgas não tem valor taxonômico, engloba microrganismos algais com clorofila a e outros pigmentos fotossintéticos, os quais são capazes de realizar a fotossíntese oxigênica, e sua caracterização (sistemática) implica a consideração de uma série de critérios (HOEK et al., 1995; RAVEN et al., 2001).
Segundo TOMASELLI (2004), estes microrganismos têm sido tradicionalmente classificados quanto aos tipos de pigmentos, a natureza química dos produtos de reserva e pelos constituintes da parede celular. Também têm sido considerados aspectos citológicos e morfológicos, tais como a ocorrência de células flageladas, a estrutura dos flagelos, os processos de formação do núcleo e da divisão celular, a presença e a caracterização de envoltório do(s) cloroplasto(s) e a possível conexão entre o retículo endoplasmático e a membrana nuclear. Além desses, técnicas de biologia molecular igualmente têm sido usadas (HU, 2004).

Sob a denominação microalgas estão incluídos organismos com dois tipos de estrutura celular: estrutura procariótica, com representantes nas Divisões Cyanophyta (cianobactérias) e Prochlorophyta; estrutura celular eucariótica, com representantes nas Divisões Chlorophyta, Euglenophyta, Rhodophyta, Haptophyta (Prymnesiophyta), Heterokontophyta (Bacillariophyceae, Chrysophyceae, Xantophyceae etc.), Cryptophyta e Dinophyta, segundo HOEK et al. (1995).

Apesar das diferenças estruturais e morfológicas entre os representantes de cada divisão, esses são fisiologicamente similares e apresentam um metabolismo análogo àquele das plantas (ABALDE et al., 1995). São principalmente encontradas no meio marinho, em água doce e no solo, sendo consideradas responsáveis por pelo menos $60 \%$ da produção primária da Terra (CHISTI, 2004).

O número exato de espécies microalgais ainda é desconhecido. Atualmente são encontradas citações relatando que podem existir entre 200.000 até alguns milhões de representantes deste grupo. Tal diversidade também se reflete na composição bioquímica e, desta forma, as microalgas são fonte de uma quantidade ilimitada de produtos (NORTON et al., 1996; PULZ \& GROSS, 2004). Cabe ressaltar que algumas espécies sintetizam compostos que podem ser altamente tóxicos para outras espécies de organismos, inclusive para o homem. Estes compostos também têm sido explorados comercialmente e são objeto de inúmeras pesquisas (TEIXEIRA, 2002).

\section{Aspectos do crescimento microalgal}

No ambiente natural, assim como nos cultivos, o crescimento de uma população microalgal é resultado da interação entre fatores biológicos, físicos e químicos (RAVEN, 1988). Os fatores biológicos estão relacionados às próprias taxas metabólicas da espécie cultivada, bem como com a possível influência de outros organismos sobre o desenvolvimento algal. 
Quanto aos fatores físico-químicos, são principalmente reportados estudos sobre iluminação, temperatura, salinidade e disponibilidade de nutrientes (HELLENBUST, 1970; GUILLARD, 1975; EPPLEY, 1977; YONGMANITCHAI \& WARD, 1991).

Segundo BOROWITZKA (1999), estes organismos podem ser cultivados em diversos sistemas de produção, com volume variando desde poucos litros até bilhões de litros. Os sistemas comumente empregados são pouco sofisticados, uma vez que muitas empresas desenvolvem cultivos a céu aberto, sob condições naturais de iluminação e temperatura, e com baixo ou nenhum controle destes parâmetros ambientais. Os tanques são geralmente rasos, construídos em concreto, fibra de vidro, policarbonato, com fundo de terra ou revestido com material plástico, sendo que as culturas são constantemente agitadas.

Recentemente, alguns cultivos têm sido desenvolvidos em equipamento específico, denominado fotobiorreator ("photobioreactor"), visando a alcançar elevadíssima produtividade. Os cultivos são realizados em sistema fechado, em painéis de forma achatada ou em serpentinas, espirais ou cilindros, construídos com tubos de plástico, vidro ou policarbonato. Nos fotobiorreatores, é possível controlar as condições de cultivo (quantidade dos nutrientes, temperatura, iluminação, $\mathrm{pH}$ etc.). Isto implica uma elevada produtividade, viabilizando a produção comercial de uma série de compostos de elevado valor (TREDICI, 2004).

Muitas das substâncias sintetizadas e acumuladas pelas microalgas são também encontradas nas plantas, as quais evoluíram das algas verdes ou clorófitas (RAVEN et al., 2001). Entretanto, segundo COHEN (1986) e RICHMOND (1990), a produção microalgal pode ser justificada por apresentar diversas vantagens, dentre as quais podem ser destacadas: o cultivo de microalgas é um sistema biológico eficiente na utilização da energia solar para a produção de matéria orgânica, sendo que, muitas espécies crescem mais rapidamente do que as plantas terrestres, fato que possibilita maiores rendimentos anuais de biomassa (maior produtividade); sua natureza unicelular assegura uma biomassa com mesma composição bioquímica, o que não ocorre com as plantas terrestres que apresentam compostos localizados em partes específicas: nos frutos, folhas, sementes ou raízes; por manipulação das condições ambientais de cultivo (luz, temperatura e nutrientes, por exemplo) muitas espécies podem ser induzidas a sintetizar e acumular altas concentrações de proteínas, carboidratos, lipídios etc. Tais compostos apresentam um elevado valor comercial, principalmente por serem produtos naturais; podem crescer bem em regiões com extremas condições climáticas. Os cultivos podem ser desenvolvidos com água marinha ou de estuários, a qual não pode ser convencionalmente empregada no cultivo de plantas com valor para a agricultura, ou com água proveniente de diversos outros processos de produção (agropecuária, indústrias, dejetos domésticos, etc.); o ciclo de vida da maioria das microalgas se completa em poucas horas, o que favorece a seleção de cepas e o melhoramento genético das espécies.

Aplicações biotecnológicas das microalgas

A aplicação mais comum tem sido na aqüicultura, para a alimentação direta ou indireta de algumas espécies de peixes, moluscos, crustáceos e de diversos organismos forrageiros de interesse econômico. São empregadas espécies de Bacillariophyceae (Chaetoceros spp. Ehrenberg, Thalassiosira spp. Cleve, Phaeodactylum tricornutum Bohlin e Skeletonema costatum Greville), Haptophyceae (Isochrysis spp. Parke), Cryptophyceae (Rhodomonas spp. Karsten), Chrysophyceae (Monochrysis spp. Skuja), Prasinophyceae (Tetraselmis spp. Stein), Cyanophyceae (Arthrospira spp. e Spirulina spp.) e Chlorophyceae (Chlorella spp., Dunaliella spp. e Scenedesmus spp. Bourrely), dentre outras classes e diversas espécies (SILVA et al., 2003; MULLER-FEUGA, 2004).

Além da consolidada produção para a obtenção de biomassa, diversas microalgas têm sido cultivadas por sua capacidade de sintetizar compostos considerados nutracêuticos, tais como os ácidos graxos poliinsaturados (ácido araquidônico - ARA, ácido eicosapentaenóico - EPA e ácido docosahexaenóico - DHA, por exemplo) e pigmentos carotenóides (astaxantina, betacaroteno, luteína, cantaxantina etc.), que apresentam propriedades terapêuticas (GILL \& VALIVETY, 1997; TRIPATHI et al., 1999). Atualmente, são comercializadas como alimento natural ou suplemento alimentar e são encontradas formulações em pó, tabletes, cápsulas ou extratos. São também incorporadas em massas, petiscos, doces, bebidas etc., tanto como suplemento nutricional quanto como corantes naturais (BECKER, 2004; COLLA et al., 2004; PULZ \& GROSS, 2004).

Para o emprego na elaboração de alimentos, bem como para a extração de alguma substância de interesse, é necessário primeiramente separar a biomassa do meio de cultura. O processo de separação envolve uma ou mais etapas sólido:líquido, como floculação, centrifugação e filtração, por exemplo. A seguir, a biomassa é desidratada. Para tanto, podem ser empregadas diversas técnicas, como a secagem ao 
sol, o "spray-drying” e a liofilização. Para a extração dos compostos, as células microalgais são rompidas, empregando métodos de homogeneização, ultra-som, choque osmótico, solventes, enzimas etc. As substâncias de interesse são então recuperadas e, na maioria dos casos, sofrem algum processo de purificação, como ultrafiltração, cromatografia ou fracionamento (MOLINA GRIMA, 2004).

Algumas espécies são bem conhecidas quanto ao potencial de cultivo e quanto aos compostos que sintetizam. Na tabela 1, são apresentados alguns produtos obtidos das microalgas.

Ácidos graxos poliinsaturados

Uma grande importância tem sido dada à provisão das fontes de ácidos graxos poliinsaturados. Isto é devido às mudanças na dieta humana, nos últimos séculos, e ao acentuado aparecimento de uma série de doenças relacionadas ao baixo consumo destes compostos, bem como a sua reconhecida significância terapêutica, especialmente àqueles da família Ômega-3 (SIMOPOULOS, 2002).
Os ácidos graxos podem ser obtidos de fontes animais ou vegetais, tanto terrestres quanto aquáticas, e diversos microrganismos têm sido considerados como uma alternativa às fontes usuais desta classe de lipídios (CERTIK \& SHIMIZU, 1999). Segundo RATLEDGE (2001), a produção de óleo a partir de organismos unicelulares ("single cell oil" - SCO) é um conceito relativamente novo, sendo que as microalgas mostram-se como uma promissora opção.

O conteúdo de lipídios da biomassa microalgal pode variar entre 1 a $40 \%$ do peso seco e, em certas condições de cultivo, pode alcançar até $85 \%$ (BECKER, 2004). Os lipídios algais são tipicamente compostos por glicerol, açúcares ou bases esterificadas e ácidos graxos contendo entre 12 e 22 carbonos, podendo ser tanto saturados quanto mono ou poliinsaturados. Os ácidos graxos correspondem à maior fração dos lipídios e, em algumas espécies, os PUFA ("polyunsaturated fatty acids") representam entre 25 e $60 \%$ dos lipídios totais (BECKER, 1988; BROWN, 1991; BECKER, 2004).

Tabela 1 - Alguns produtos obtidos de microalgas.*

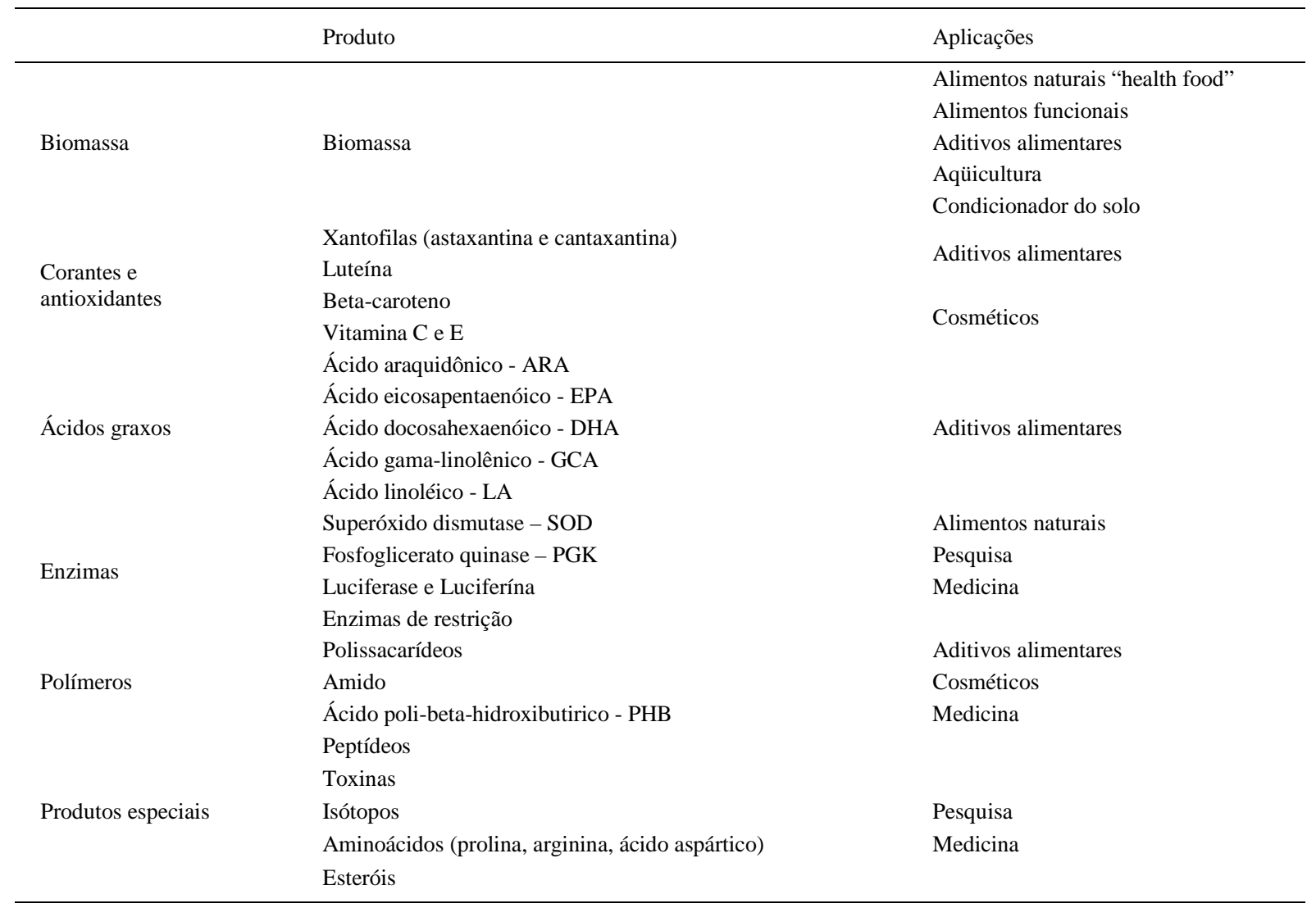

* Adaptado de BARBOSA (2003). 
Os lipídios de algumas espécies (quase sempre marinhas) contêm quantidades relativamente altas de ácidos graxos poliinsaturados de cadeia longa, notadamente de EPA (20:5 n-3) e DHA (22:6 n-3) (VOLKMAN et al., 1989; ZHUKOVA\& AIZDAICHER, 1995; ROBLES MEDINA et al., 1998).

JIANG et al., (1999) relatam que a significância terapêutica dos PUFA tem sido demonstrada por diversos estudos clínicos e epidemiológicos. Ao EPA e ao DHA, são atribuídas propriedades benéficas à saúde, associadas ao consumo de certos peixes marinhos e seus óleos. Os PUFA têm função na prevenção e tratamento de uma série de doenças cardiovasculares, da aterosclerose e da arritmia, da redução da pressão arterial, da redução dos níveis de colesterol e triglicerídios no plasma, da artrite reumatóide, do câncer e são aparentemente essenciais na nutrição infantil e no desenvolvimento cerebral (PIGOTT \& TUCKER, 1990; RADWAN, 1991; BOROWITZA, 1993; FÁBREGAS et al., 1994; FRANKE et al., 1994; GILL \& VALIVETY, 1997; SIMOPOULOS, 2002).

Os peixes marinhos são uma conhecida fonte destes compostos nutricionalmente muito importantes. Entretanto, existem consideráveis evidências indicando que os ácidos graxos poliinsaturados encontrados nos óleos de peixes provêm da ingestão de organismos que constituem o zooplâncton, os quais têm as microalgas como seu principal alimento. Desta maneira, através da cadeia trófica, os PUFA sintetizados e acumulados pelas microalgas são direcionados até os peixes (ROBLES MEDINA et al., 1998).

Peixes como bacalhau, savelha, arenque, anchova e sardinha contêm uma alta proporção de gordura e são empregados na obtenção de PUFA. No entanto, os produtos extraídos destas fontes podem apresentar vários problemas, tais como: odor desagradável, contaminação com metais pesados, baixa estabilidade, presença de colesterol, produção variável e um complexo perfil de ácidos graxos, podendo apresentar mais de 50 tipos diferentes (ROBLES MEDINA et al., 1998). Em contraste, os ácidos graxos das microalgas não apresentam as desvantagens citadas. Além disso, nos cultivos, as condições ambientais podem ser controladas e as espécies selecionadas de acordo com o(s) ácido(s) graxo(s) desejado(s). Ademais por apresentar composição mais simples, o processo de purificação dos PUFA é facilitado (ZITTELLI et al., 1999; WEN \& CHEN, 2003).

Dentre as espécies conhecidas de microalgas que apresentam quantidades significativas de PUFA das famílias Ômega-3 e Ômega-6, encontramse representantes de Haptophyceae (Isochrysis spp. e Pavlova lutheri (Droop) Green), Bacillariophyceae (Phaeodactylum tricornutum, Thalassiosira spp. e Odontella aurita (Lyngbye) Agardh), Dinophyceae (Crypthecodinium cohnii (Seligo) Javornick), Rhodophyceae (Porphyridium cruentum Nägeli) e, em menor quantidade, de Chlorophyceae (YONGMANITCHAI \& WARD, 1991). Segundo PULZ \& GROSS (2004), os ácidos graxos poliinsaturados de origem microalgal têm um mercado muito promissor na biotecnologia, em especial na indústria de alimentos funcionais.

\section{Carotenóides}

Semelhantemente ao que ocorre em outros organismos, cada classe de microalgas apresenta sua própria combinação de pigmentos e, conseqüentemente, coloração distinta. Os três principais grupos de pigmentos encontrados na biomassa microalgal são as clorofilas, os carotenóides e as ficobilinas (ficobiliproteínas) (ABALDE et al., 1995). Segundo BOROWITZKA (1993), é possível incrementar a síntese destes compostos através da manipulação das condições de cultivo, usualmente por algum estresse ambiental.

Os carotenóides, pigmentos de grande interesse comercial, funcionam como fotoprotetores e como pigmentos fotossintéticos secundários, sendo que cada espécie pode conter entre 5 e 10 tipos de um universo de aproximadamente 60 diferentes carotenóides presentes nas células microalgais. Diversas espécies podem acumular grande concentração de betacaroteno, astaxantina ou cantaxantina, por exemplo, os quais têm uma ampla aplicação como corantes naturais e como antioxidantes (BAKER \& GUNTER, 2004; PULZ \& GROSS, 2004).

$\mathrm{O}$ crescente interesse industrial por esses pigmentos naturais pode ser explicado pela capacidade atribuída a eles de prevenir doenças degenerativas: combatendo os radicais livres e funcionando como agentes anticâncer e estimuladores do sistema imunológico (OROSA et al., 1997). Comparados aos corantes sintéticos, são mais resistentes à presença de ácido ascórbico, ao calor, aos processos de congelamento e apresentam eficiência mesmo quando aplicados nos alimentos em pequenas quantidades (SKULBERG, 2004). A rígida regulamentação para a aplicação de corantes sintéticos, na indústria de alimentos, estimula pesquisas visando ao desenvolvimento produtivo e ao uso de carotenóides microalgais como aditivo alimentar (CAMPO et al., 2000). 
Betacaroteno

O betacaroteno é um pigmento tipicamente encontrado nas microalgas, bem como nas macroalgas e nas plantas. Geralmente é encontrado numa fração inferior a $1 \%$ da massa seca, mas pode ser acumulado até aproximadamente $10 \%$ em espécies halotolerantes (crescem em elevada concentração de sal), como naquelas do gênero Dunaliella (ABALDE et al., 1995). Este composto, extraído da biomassa microalgal, vem sendo aplicado comercialmente como corante natural, podendo atuar como pró-vitamina A, produto antioxidante e contra doenças degenerativas como o câncer (EDGE et al., 1997; BEN-AMOTZ, 2004).

A espécie D. salina é reconhecidamente uma importante fonte de betacaroteno. O cultivo comercial é realizado de maneira eficiente em tanques abertos, em regiões de salinas, onde a elevada incidência luminosa e a alta salinidade geram um estresse (desequilíbrio osmótico) nas células, que respondem com a síntese de glicerol e betacaroteno (BOROWITZA \& BOROWITZA, 1988).

O betacaroteno de fonte microalgal tem sido comercializado sob três formas: extratos, pó e como biomassa seca. Segundo BEN-AMOTZ (2004), o preço deste produto varia entre US\$300,00 e US\$3.000,00 por quilograma, de acordo com a qualidade do produto e a demanda.

\section{Astaxantina}

A espécie Haematococcus pluvialis tem sido cultivada comercialmente devido a sua capacidade de acumular astaxantina sob condições de estresse ambiental como deficiência de nitrogênio e elevada intensidade luminosa (CORDERO-ESQUIVEL et al., 1996). Segundo BOROWITZKA \& BOROWITZA (1988), H. pluvialis pode conter entre 1,5 e 3\% de astaxantina na biomassa seca. No mercado, são encontrados produtos na forma de concentrados em pó, liofilizados ou biomassa desidratada, bem como extrato em óleo vegetal.

O maior mercado para a astaxantina tem sido a aquiicultura, onde é especialmente empregada para dar a cor avermelhada à carne do salmão cultivado (TRIPATHI et al., 1999). Segundo CYSEWSKI \& LORENZ (2004), a astaxantina natural é vendida por aproximadamente US\$2.500,00 o quilograma, sendo que $95 \%$ do consumo mundial da aqüicultura são abastecidos com astaxantina sintética. Como existe em nível mundial uma crescente procura por produtos naturais, as empresas produtoras de astaxantina (extraída das microalgas) percebem isso como uma grande oportunidade comercial (MARGALITH, 1999).
O interesse pela produção e comercialização da astaxantina microalgal visando ao consumo humano também tem aumentado, pela iminência na aprovação pelo U S Food and Drug Administration (FDA), para o uso como ingrediente em suplementos dietéticos e por sua aprovação em diversos países europeus (CYSEWSKI \& LORENZ, 2004).

Além do betacaroteno e da astaxantina, outros pigmentos como as ficobiliproteínas, notadamente a ficoeritrina (de coloração avermelhada), sintetizada por Cyanophyta, Rhodophyta e Cryptophyta, e a ficocianina (de coloração azulada / avermelhada) produzida por Cyanophyta, Rhodophyta, Cryptophyta e Glaucophyta, têm sido empregados como corantes na indústria de alimentos, na indústria de cosméticos e em ensaios imunológicos (BECKER, 2004).

Outras aplicações

Afora as aplicações relacionadas ao emprego das microalgas e dos produtos extraídos destas na indústria de alimentos, muitos estudos vêm sendo realizados nos mais diversos campos, tais como: no tratamento de águas residuais de inúmeros processos industriais, para a detoxificação biológica e remoção de metais pesados; como bioindicadores, na detecção de nutrientes (para as microalgas) e substâncias tóxicas (detergentes, efluentes industriais, herbicidas etc.). Na agricultura, a biomassa pode ser empregada como biofertilizante do solo. Além de sintetizar toxinas, as microalgas podem produzir uma gama de moléculas bioativas com propriedades antibióticas, anticâncer, antiinflamatórias, antivirais, redutoras do colesterol, enzimáticas e com outras atividades farmacológicas. Além disso, podem ser usadas na mitigação do efeito estufa, pela assimilação do $\mathrm{CO}_{2}$, resultado do processo de queima dos combustíveis fósseis e de práticas agrícolas impróprias (as queimadas, por exemplo). Ainda, possibilitam produção de biocombustíveis (biodiesel, por exemplo). Por fim as microalgas são úteis a produção de hidrogênio livre, por biofotólise na elaboração de um inseticida natural, pela recombinação de uma sequiência do DNA da bactéria Bacillus thuringiensis var. israelensis (Bti) no genoma de uma espécie de microalga, consumida pelo mosquito da malária em sua forma larval.

\section{CONSIDERAÇÕES FINAIS}

O cultivo de microalgas para a obtenção de biomassa e de seus produtos de síntese trata-se de uma atividade industrial estabelecida em escala comercial em alguns países e a produção está a cargo de grandes empresas. Na tabela 2, são apresentados 
Tabela 2 - Empresas, localização, microalgas cultivadas, seus produtos e atividade biológica atribuída*.

\begin{tabular}{|c|c|c|c|c|}
\hline Empresa & País & $\begin{array}{l}\text { Microalga } \\
\text { (gênero) }\end{array}$ & Produto & Atividade biológica \\
\hline Martek/Omegatech & USA & Crypthecodinium & DHA & Desenvolvimento cerebral \\
\hline Cyanotech & USA & Haematococcus & Astaxantina & Tratamento da Síndrome do Túnel do Carpo \\
\hline MERA & USA & Haematococcus & Astaxantina & Antiinflamatório, tratamento de lesões musculares \\
\hline OceanNutrition & Canadá & Chlorella & Extrato de carboidratos & Melhora da resposta imunológica, antigripal ("anti-flu") \\
\hline InnovalG & França & Odontella & EPA & Antiinflamatório \\
\hline Panmol/Madaus & Aústria & Spirulina & Vitamina $\mathrm{B}_{12}$ & Melhora da resposta imunológica \\
\hline Nutrinova/Celanese & Alemanha & Ulkenia & DHA & Tratamento de doenças cerebrais e cardíacas \\
\hline
\end{tabular}

*Adaptado de PULZ \& GROSS, 2004.

os nomes de algumas empresas, sua localização, as microalgas cultivadas, os produtos e as atividades biológicas destes produtos.

Apesar de ser uma atividade consolidada em outros países, a produção comercial de microalgas no Brasil tem sido realizada por empresas (localizadas no litoral de Santa Catarina e de praticamente todos os Estados da Região Nordeste) que produzem a biomassa e a empregam principalmente na alimentação de organismos como camarões e moluscos marinhos. Não há informações da produção em grande escala para a obtenção de biomassa ou para a extração de compostos bioativos visando a outras aplicações. Somente existem iniciativas ainda de caráter experimental em diversos centros de pesquisa e, em geral, trabalhando isoladamente.

Além das substâncias conhecidas, a quantidade de compostos de interesse comercial que podem ser obtidos das microalgas parece ser imprevisível. Em nível mundial, o crescente interesse em tecnologias limpas, sustentáveis e orgânicas, na obtenção de produtos para o consumo humano, demanda uma contínua busca por espécies e/ou variedades capazes de sintetizar grandes quantidades de compostos específicos e de como é possível potencializar a biossíntese destes (condições de cultivo, melhoramento genético etc.). Igualmente, há a necessidade de pesquisas visando ao desenvolvimento e, principalmente, ao aperfeiçoamento dos sistemas de produção em escala comercial, a fim de tornar comercialmente viáveis alguns dos sistemas conhecidos. Essas pesquisas, por fim, também, se fazem necessárias à identificação dos produtos que podem ser extraídos das microalgas, da possível atividade biológica (estudos metabológicos e toxicológicos) e do desenvolvimento de mercados específicos para estes.

\section{REFERÊNCIAS}

ABALDE, J. et al. Microalgas: cultivo e aplicaciones. España: Universidade da Coruña, 1995. 210p. (Monografías n.26).

BAKER, R.; GUNTER, C. The role of carotenoids in consumer choice and the likely benefits from their inclusion into products for human consumption. Trends in Food Science \& Technology, n.15, p.484-488, 2004

BARBOSA, M.J.G.V. Microalgal photobioreactors: scaleup and optimisation. 2003, 166f. Tese (Doutorado em Ciências) - Wageningen University.

BECKER, E.W. Micro-algae for human and animal consumption. In: BOROWITZKA, M.A.; BOROWITZKA, L.J. (Eds). Micro-algal biotecnology. Cambridge: Cambridge University, 1988. p.222-256.

BECKER, W. Microalgae in human and animal nutrition. In: RICHMOND, A. (Ed). Handbook of microalgal culture: biotechnology and applied phycology. London: Blackwell Science, 2004. p.312-351.

BEN-AMOTZ, A. Industrial production of microalgal cellmass and secondary products - major industrial species: Dunaliella. In: RICHMOND, A. (Ed). Handbook of microalgal culture: biotechnology and applied phycology. Oxford: Blackwell Science, 2004. p.273-280.

BOROWITZKA, M.A.; BOROWITZKA, L.J. (Eds). Microalgal biotechnology. Cambridge: Cambridge University, 1988. $477 \mathrm{p}$.

BOROWITZKA, M.A. Products from microalgae. Infofish International, v.5, p.21-26, 1993.

BOROWITZKA, M.A. Commercial production of microalgae: ponds, tanks, tubes and fermenters. Journal of Biotechnology, v.70, p.313-321, 1999.

BROWN, M.R. The amino-acid and sugar composition of 16 species of microalgae used in mariculture. Journal of Experimental Marine Biology and Ecology, v.145, p.7999, 1991.

BRUNO, J.J. Edible microalgae: a review of the health research. Pacifica: Center for Nutritional Psychology, 2001 V.3, 56p. 
CAMPO, J.A. et al. Carotenoid content of chlorophycean microalgae: factors determining lutein accumulation in Muriellopsis sp. (Chlorophyta). Journal of Biotechnology, v.76, n.1, p.51-59, 2000.

CERTIK, M.; SHIMIZU, S. Biosynthesis and regulation of microbial polyunsaturated fatty acid production. Journal of Bioscience and Bioengineering, v.87, n.1, p.1-14, 1999.

CHISTI, Y. Microalgae: our marine forests. Book reviews. RICHMOND, A. (Ed). Handbook of microalgal culture: biotechnology and applied phycology. Oxford: Blackwell Science, 2004. 566p.

COHEN, Z. Products from microalgae. In: RICHMOND, A (Ed). CRC Handbook of microalgal mass culture. Boca Raton: CRC, 1986. p.421-454.

COLLA, L.M. et al. Fatty acids of Spirulina platensis grown under different temperatures and nitrogen concentrations. Zeitschrift für Naturforschung, v.59c, p.55-59, 2004.

CORDERO-ESQUIVEL, B. et al. Astaxanthin production from the green alga Haematococcus pluvialis with different stress conditions. Biotechnology Letters, v.2, n.18, p.213-218, 1996.

CYSEWSKI, G.R.; LORENZ, R.T. Industrial production of microalgal cell-mass and secondary products - species of high potential: Haematococcus. In: RICHMOND, A. (Ed). Handbook of microalgal culture: biotechnology and applied phycology. Oxford: Blackwell Science, 2004. p.281-288.

EDGE, R. et al. The carotenoids as antioxidants: a review. Journal of Photochemistry and Photobiology B: Biology, n.41, p.189-200, 1997.

EPPLEY, R.W. The growth and Culture of diatoms. In: WERNER, D. (Ed). The biology of diatoms. Berkeley: University of California, 1977. p.24-64. (Botanical Monographs, v.13).

FÁBREGAS, J. et al. Decrease of plasma cholesterol with the marine microalgae Dunaliella tertiolecta in hypercholesterolemic rats. Journal of General Microbiology, n.40, p.553-540, 1994.

FRANKE, H. et al. Polyunsaturated fatty acids from microalgae. International Food Ingredients, n.4, p.46-52, 1994.

GILL, I.; VALIVETY, R. Polyunsaturated fatty acids, part 1: occurrence, biological activities and applications. Trends in Biotechnology, n.15, p.401-409, 1997.

GROBBELAAR, J.U. Algal biotechnology: real opportunities for Africa. South African Journal of Botany, v.70, n.1, p.140-144, 2004.

GUILLARD, R.R.L. Culture of phytoplankton for feeding marine invertebrates. In: SMITH, W.L.; CHANLEY, M.H. (Eds). Culture of marine invertebrate animals. New York: Plenum, 1975. p.29-60.

HELLENBUST, J.A. Ligth: plants. In: KINNE, O. (Ed). Marine ecology. A comprehensive integrated treatise on life in oceans and coastal waters. London: Wiley Interscience, 1970. p.124-158.

HOEK, C. van den et al. Algae: an introduction to phycology. London: Cambridge University, 1995. 623p.
HU, Q. Industrial production of microalgal cell-mass and secondary products - major industrial species: Arthrospira (Spirulina) platensis. In: RICHMOND, A. (Ed). Handbook of microalgal culture: biotechnology and applied phycology. Oxford: Blackwell Science, 2004. p.264-272.

JIANG, Y. et al. Production potential of docosahexaenoic acid by heterotrophic dinoflagelate Crypthecodinium cohnii. Process Biochemistry, v.34, p.633-637, 1999.

JOURDAN, J.P. Cultivez votre spiruline - manuel de culture artisanale, 1996. Capturado em 20 mar. 2004. Online. Disponível na Internet http://www.spirulinasource.com/cultivez.

KIRK, E.A.; BEHRENS, P.W. Commercial developments in microalgal biotechnology. Journal of Phycology, n.35, p.215226, 1999.

LEMAN, J. Oleaginous microorganisms: an assessment of the potential. Advances in Applied Microbiology, v.51, p.195243, 1997.

MARGALITH, P.Z. Production of ketocarotenoids by microalgae. Applied Microbiology Biotechnology, v.51, p.431-438, 1999.

MOLINA GRIMA, E. et al. Downstream processing of cellmass and products. In: RICHMOND, A. (Ed). Handbook of microalgal culture: biotechnology and applied phycology. Oxford: Blackwell Science, 2004. p.215-251.

MULLER-FEUGA, A. Microalgae for aquaculture. In: RICHMOND, A. (Ed). Handbook of microalgal culture: biotechnology and applied phycology. Oxford: Blackwell Science, 2004. p.352-364.

NORTON, T.A et al. Algal biodiversity. Phycologia, n.35, p.308-326, 1996.

OROSA, M. et al. Production and analysis of secondary carotenoids in green algae. Journal of Applied Phycology, n.12, p.553-556, 1997.

PIGOTT, G.M.; TUCKER, B.W. Seafood: effects of technology on nutrition. New York: Marcel Dekker, 1990. $362 \mathrm{p}$.

PULZ, O.; GROSS, W. Valuable products from biotechnology of microalgae. Applied Microbiology Biotechnology, v.65, p.635-648, 2004.

RADWAN, S.S. Sources of C20-polyunsaturated fatty acids for microbiological use. Applied Microbiology Biotechnology, n.35, p.421-430, 1991.

RATLEDGE, C. Microorganisms as source of polyunsaturated fatty acids. In: GUNSTONE, F.D. (Ed). Structured and modified lipids. New York: Marcel Dekker, 2001. p.351399.

RAVEN, J.A. Limits to growth. In: BOROWITZKA, M.A.: BOROWITZKA, L.J. (Eds). Micro-algal biotecnology. Cambridge: Cambridge University, 1988. p.331-356.

RAVEN, P.H. et al. Biologia vegetal. 6.ed. Rio de Janeiro: Guanabara Koogan, 2001. 906p. 
RICHMOND, A. Spirulina. In: BOROWITZKA, M.A.; BOROWITZKA, L.J. (Eds). Micro-algal biotecnology. Cambridge: Cambridge University, 1988. p.85-121.

RICHMOND, A. (Ed). CRC Handbook of microalgal mass culture. Florida: CRC, 1990. 528p.

RICHMOND, A. (Ed). Handbook of microalgal culture: biotechnology and applied phycology. Oxford: Blackwell Science, 2004. 566p.

ROBLES MEDINA, A. et al. Downstream processing of algal polyunsaturated fatty acids. Biotechnology Advances, v.16, n.13, p.517-580, 1998.

SILVA, F.C. et al. Cultivo de microalgas marinhas. In: POLI, C.R. et al. (Orgs). Aqüicultura: experiências brasileiras. Florianópolis: Multitarefa, 2003. p.93-120.

SIMOPOULOS, A.P. The importance of the ratio of omega-6/ omega-3 essential fatty acids. Biomedecine \& Pharmacotherapy, v.56, n. 8, p.365-379, 2002.

SKULBERG, O.M. Bioactive chemicals in microalgae. In: RICHMOND, A. (Ed). Handbook of microalgal culture: biotechnology and applied phycology. Oxford: Blackwell Science, 2004. p.485-512.

TEIXEIRA, V.L. Produtos naturais marinhos. In: PEREIRA, R.G.; SOARES-GOMES, A. (Orgs). Biologia marinha. Rio de Janeiro: Interciência, 2002. p.249-279.
TOMASELLI, L. The microalgal cell. In: RICHMOND, A. (Ed). Handbook of microalgal culture: biotechnology and applied phycology. Oxford: Blackwell Science, 2004. p.3-19.

TREDICI, M.R. Mass production of microalgae: photobioreactors. In: RICHMOND, A. (Ed). Handbook of microalgal culture: biotechnology and applied phycology. Oxford: Blackwell Science, 2004. p.178-214.

TRIPATHI, U. et al. Production of astaxanthin in Haematococcus pluvialis cultured in various media. Bioresource Technology, n.68, p.197-199, 1999.

VOLKMAN, J.K. et al. Fatty acid and lipid composition of 10 species of microalgae used in mariculture. Journal of Experimental Marine Biology and Ecology, v.128, p.219$240,1989$.

WEN, Z.Y; CHEN, F. Heterotrophic production of eicosapentaenoic acid by microalgae. Biotechnology Advances, v.21, p.273-294, 2003.

YONGMANITCHAI, W.; WARD, O.P. Screening of algae for potential alternative sources of eicosapentaenoic acid. Phytochemistry, v.9, n.30, p.2963-2967, 1991.

ZITTELLI, G.C. et al. Production of eicosapentaenoic acid by Nannochloropsis sp. cultures in tubular photobioreactors. Journal of Biotechnology, v.70, p.299-312, 1999.

ZHUKOVA, N.V.; AIZDAICHER, N.A. Fatty acid composition of 15 species of marine microalgae. Phytochemistry, v.39, n.2, p.351-356, 1995 